\title{
Doutrina da Proteção Integral e Criminologia Brasileira: A Sujeição Criminal do Adolescente Suspeito
}

\author{
Érica Babini Lapa do Amaral Machado \\ Doutorado e Mestrado em Ciências Criminais (Ufpe). Professora da Graduação e Pós-Graduação Stricto Sensu da Universidade \\ Católica de Pernambuco (Unicap). http://lattes.cnpq.br/7784333143703014. ericababini@ hotmail.com

\section{Maurilo Sobral Neto} \\ Mestrado em Direito pela Universidade Católica de Pernambuco (2017). Professor do Centro Universitário Maurício de Nassau/Reci- \\ fe, Brasil. Membro do coletivo Butuka. Pesquisador do Grupo Asa Branca de Criminologia. http://lattes.cnpq.br/7462478304351633. \\ maurilosobral@gmail.com
}

O trabalho discute como a Doutrina da Proteção Integral opera na América Latina, cuja tônica é marcada pela falta de expectativas educacionais e de inserção no mundo do trabalho, principalmente para os que habitam as periferias brasileiras. O marco teórico é da criminologia crítica que, considerando a interdisciplinaridade e incompletude da sua conceituação e a necessidade de uma criminologia brasileira, abre-se para novos instrumentais analíticos. $O$ conceito de sujeição criminal de Michel Misse auxilia nesse sentido, na medida em que aponta que o acúmulo histórico de uma dada realidade pode levar a um tipo social negativo, avaliado independentemente de condutas. Ao associar os instrumentais teóricos, ante a atuação do adolescente em conflito com a lei, a hipótese que se apresenta é que, desde a polícia, um processo de suspeição é instaurado, pois leva em conta um padrão normal de juventude. Desse modo, a partir de revisão bibliográfica objetiva-se identificar mecanismos que despertam a figura do adolescente suspeito. Pretende-se discutir, também, a partir de observação etnográfica que está em curso na Gerência de Polícia da Criança e do Adolescente da cidade do Recife/PE, achados iniciais que apontam para a construção social do adolescente suspeito. A conclusão é que o discurso jurídico da proteção integral, ante as especificidades da sociedade brasileira, pode ter criado uma retórica que oculta uma prática social que reifica o adolescente.

Palavras-chave: Doutrina da proteção integral. Adolescente suspeito. Criminologia crítica brasileira. Sujeição criminal.

\section{DOCTRINE OF INTEGRAL PROTECTION AND BRAZILIAN CRIMINOLOGY: THE CRIMINAL SUBJECTION OF CHILD SUSPECT}

\section{ABSTRACT}

This paper discusses the function of Doctrine of Integral Protection in Latin America, a place where work and education are scant, specially for those whom lives in the poor areas. The theoretical lens to interpret this work is the critic criminological which needs others analytics tool given by Brazil reality, whereas your incompleteness. Then, criminal subjection, a concept developed by Michel Miss, is used to foresight a interpretation that tracks are made by a historical accumulation taking to a specific social type denied in social spaces, whom can be criminalized independent of your conduct. When the theoretical lens - Brazilian critical criminological and criminal subjection - are both used, a hypothesis arises: in the Criminal Justice System, since from police a suspect process is done, because a youth pattern is activated. To investigate it was made literature review and ethnographic observation in the Police Management of Children and Adolescents in Recife/PE. The authors conclude that the judicial discourses of integral protection, face to Brazil violent reality, is a rethoric way to hide a pratice of the Criminal System to objectify the adolescent whom diverges of youth pattern.

Keywords: Integral protection doctrine. Suspect-child. Brazilian criminology. Criminal subjection.

\section{SUMÁRIO}

1 Doutrina da Proteção Integral: O Discurso Jurídico Universal de Proteção de Direitos Humanos. 2 Criminologia Crítica e Limites: Abrindo Possibilidades a Partir do Brasil. 2.1 O "Assombroso Transplante" e a Função de Contenção - Discurso Criminológico no Brasil. 3 "Sujeição Criminal”: O Acúmulo Histórico-Social Brasileiro e a Autonomização do Rótulo - Uma Experiência Etnográfica. 3.1 Uma Experiência Etnográfica na Cidade do Recife - A Concretização da Sujeição Criminal. 4 O Discurso Jurídico (Proteção Integral) e a Normalização da Juventude: A Reificação do Adolescente Suspeito. 5 Referências. 


\section{DOUTRINA DA PROTEÇÃO INTEGRAL: O DISCURSO JURÍDICO UNIVERSAL DE PROTEÇÃO DE DIREITOS HUMANOS}

A Convenção dos Direitos da Criança (CDC) de 1989 representou o marco de superação do paradigma punitivo, cientificista, tutelar, eufêmico e excludente do período anterior, considerado menorista.

Todas essas legislações são fundadas nos valores e direitos humanos e impulsionam perspectivas de autonomia e garantia, afastando-se dos métodos repressivos para uma orientação educativa, constituindo um programa de ação - seja como princípio, seja como teoria - que assegura, com absoluta prioridade, os direitos individuais e as garantias fundamentais inerentes à criança e ao adolescente, por serem sujeitos de direitos, o que implica uma dedicação protetiva diferenciada.

Nesse sentido, a Convenção propõe uma transformação no sentido de conceder autonomia ao adolescente, o qual, consequentemente, assume as responsabilidades de seus atos, em conformidade com sua idade, exatamente porque dificilmente alguém pode constituir-se cidadão se não compreende de alguma maneira os desvalores e valores de seus próprios atos no seio da comunidade em que vive.

A proteção jurídica especializada é fundamentada no respeito à peculiar condição de desenvolvimento, devendo ser, desse modo, integral a proteção ao desenvolvimento individual da personalidade nos seus aspectos físico, mental, moral espiritual e social (MACHADO, 2003).

O reconhecimento da especialidade dos sujeitos trouxe essa nova concepção principiológica, expressa pelos princípios do Interesse Superior da Criança e da Prioridade Absoluta, isto é, o rápido atendimento, e transversalidade, demandando sinergia de todos os atores sociais: Estado, comunidade e família, os quais, participativamente, concretizam a democracia. Tais premissas estão constitucionalmente asseguradas no artigo 227 (reproduzido pelo artigo $4^{\circ}$ do ECA).

É fundamental, portanto, a constitucionalização do direito da criança, fundada em dois aspectos - o quantitativo, relacionado à positivação de direitos fundamentais exclusivos de crianças (que se configuram como direitos da personalidade infantil) ${ }^{1}$ e o qualitativo, constituindo o direito das crianças uma manifestação de direitos humanos.

Ocorre que, quando a Doutrina da Proteção Integral engendrou a construção universalizada do período da infância, dirigiu a especialização do alvo da Justiça àquele não enquadrado ao conceito geral. Nesse sentido, três classes da infância se estabeleceram, as que estão

\footnotetext{
Apresentados no artigo 227, §3: O direito à proteção especial abrangerá os seguintes aspectos: I - idade mínima de quatorze anos para admissão ao trabalho, observado o disposto no art. 7으, XXXIII; II - garantia de direitos previdenciários e trabalhistas; III - garantia de acesso do trabalhador adolescente e jovem à escola; IV - garantia de pleno e formal conhecimento da atribuição de ato infracional, igualdade na relação processual e defesa técnica por profissional habilitado, segundo dispuser a legislação tutelar específica; V - obediência aos princípios de brevidade, excepcionalidade e respeito à condição peculiar de pessoa em desenvolvimento, quando da aplicação de qualquer medida privativa da liberdade; VI estímulo do poder público, através de assistência jurídica, incentivos fiscais e subsídios, nos termos da lei, ao acolhimento, sob a forma de guarda, de criança ou adolescente órfão ou abandonado; VII - programas de prevenção e atendimento especializado à criança, ao adolescente e ao jovem dependente de entorpecentes e drogas afins.
} 


\section{Humanos e}

Democracia

incluídas na sociedade e na família (normalizadas), as que estão em perigo, demandando assistência estatal e para elas devem ser aplicadas medidas protetivas do artigo 94 do ECA, e as crianças tidas como perigosas, que praticam ato infracional ( $\mathrm{SCHUCH}, 2005)$.

Essa diferenciação, apesar de ter garantido o afastamento do termo "menor" e a superação da Doutrina da Situação Irregular, implicou a reordenação dos atores jurídicos quanto à infância pobre, acentuando a perigosidade como característica do desvio juvenil, culpabilizando a família e o infrator para legitimar a intervenção estatal.

Isto é, a associação da assistência social com a responsabilização mantém a categoria menor em que a pobreza ${ }^{2}$ catalisa o tratamento do adolescente em conflito com a lei, ensejando "a manutenção do público-alvo a quem essa proposta se destina reitera o pressuposto de que os destinatários dos discursos e das práticas de correção de desvios são os adolescentes pobres" (DE PAULA, 2015, p. 41), como uma permanência, com outras roupagens, da questão do menor.

Então, na medida em que se categoriza tipos de infância, tipos de família, tipos de pessoas, tipos de relacionamento, tipos de responsabilidade, constrói-se o domínio judicial da infância, formando-se "perfis", de modo que, se há alguma criança ou adolescente "fora do lugar ideal" das caracterizações, cabe ao Judiciário promover sua alocação para aquilo que se considera normal.

O resultado, a partir dessa completude empreendida pelo Judiciário, é a associação do sistema de valores da relação parental, modelo característico das famílias nucleares burguesas em que os magistrados estão inseridos, ${ }^{3}$ à legislação, formando um padrão que guia a integração social da infância, de responsabilidade do Judiciário, cujo papel é de guardião de tudo que possa ameaçar a infância, sejam crianças em perigo, sejam crianças perigosas .

Essa diferenciação em categorias, se associada ao medo e à insegurança social, faz com que a compaixão e a repressão sejam os valores fundamentais do ECA, de modo que a regulação dos estereótipos seja fundamental - bom e mal - autorizando o Judiciário a dominar a questão da infância (SCHUCH, 2005).

Essa problemática é ainda mais acentuada no quadro social da América Latina, cuja tônica é marcada pela falta de expectativas educacionais e de inserção no mundo do trabalho, principalmente para os que habitam as periferias brasileiras, e que o desvio aparece como uma trajetória tentadora, o que, somado ao ambiente de arbítrio e insegurança - padrão de violência e negação de direitos fundamentais - faz desses jovens excluídos morais, e não sujeitos de direitos (SOARES; BILL; ATHAYDE, 2005).

\footnotetext{
Como salienta Michel Misse (2011), pobreza e criminalidade são variáveis, tidas, pelas ciências sociais, como causas a partir do século 19, subsuindo a patologia médica (lombrosiana) pela patologia social.

3 O Censo mais atualizado da magistratura brasileira, realizado pelo CNJ, cuja coleta de dados é referente a 2013 e contou com a participação de $64 \%$ do magistratura ativa no país, aponta um perfil no seguinte sentido: em geral, são homens, que ingressaram na magistratura com cerca de 34 anos, contando, em 2013, com média de 45 anos, com cerca de 10 anos de atividade na magistratura. São pessoas que se declaram majoritariamente $(80,9 \%)$ brancas, contraponto a $19,1 \%$ de negros; pessoas que já têm filhos, independentemente de homem (78,5\%) ou mulher (70,7\%). Quanto ao estado civil, $64,1 \%$ dos magistrados e $39,5 \%$ das magistradas são casados (CNJ, 2014).
} 
A criação deste ser inferior e desqualificado (decorrente do racismo, da pobreza, do não acesso à educação e aos bens essenciais à dignidade da pessoa humana) ante os mais bem colocados socialmente, deixa evidente uma sociedade hierarquizada, na qual os vínculos de comunidade são esgarçados pela desigualdade e degradação. O que é pior, poré:, esta invisibilidade ameniza o sentimento de culpa social, posto que, não sendo sujeito moral, não há grande problema em ser privado do conjunto de direitos de todos os outros cidadãos. E assim "Como, então, enfrentar o problema do adolescente infrator sem incorrer no cinismo do 'retribucionismo hipócrita' ou na consequência do 'paternalismo ingênuo'?" (VIEIRA, 1997, p. 99).

Ao lado desse cenário, não havendo a universalização de direitos, a tendência é existir classificações produtoras de desigualdades, ou seja, despolitizando os direitos em nome de uma igualdade universal, ontológica, dos seres humanos, termina-se por esquecer as circunstâncias particulares das necessidades de direito. Ou seja, há um imenso idealismo da infância, cujo discurso simbolicamente protetivo resulta num sistema de segregação e privação autoritária da liberdade.

O protagonista condutor deste processo de proteção social tardia, que o faz via segurança pública, visando à padronização de proteção integral do adolescente para tirá-lo da condição invisível, é permeado de crenças e valores pessoais e subjetivos que não podem ser desconsiderados, quando se pensa em ações humanas.

Frente a esse mundo de objetos, pessoas, acontecimentos ou ideias, não somos (apenas) automatismos, nem estamos isolados num vazio social: partilhamos esse mundo com os outros, que nos servem de apoio, às vezes de forma convergente, outras pelo conflito, para compreendê-lo, administrá-lo ou enfrentá-lo. Eis por que as representações sociais são tão importantes na vida cotidiana... Elas circulam nos discursos, são trazidas pelas palavras e veiculadas em mensagens e imagens midiáticas, cristalizadas em condutas e em organizações materiais e espaciais (JODELET apud PORTO, 2006, p. 273).

Pautando-se nesta questão, a problemática apontada pelos autores é que o discurso jurídico da proteção integral, diante das especificidades da sociedade brasileira, pode ter criado uma retórica que oculta uma prática social normalizadora que reifica o adolescente suspeito.

Para analisar a hipótese de que a força do rótulo de criminoso se impõe, força esta operada num contexto de desigualdades sociais, econômicas, de raça e gênero, como o é na realidade brasileira, foi utilizado o marco teórico da criminologia crítica, mas não somente.

Dada a interdisciplinaridade e incompletude da conceituação crítico-criminológica, sobretudo a necessidade de uma criminologia brasileira (ANDRADE, 2012), atenta às especificidades locais, percebeu-se a necessidade do manejo dos instrumentais analíticos do conceito de sujeição criminal de Michel Misse (1999), a fim de compreender como a autonomização de um rótulo de "bandido", na expressão de Misse, é operada num discurso de proteção integral. Sigamos na construção do raciocínio.

\section{CRIMINOLOGIA CRÍTICA E LIMITES: ABRINDO POSSIBILIDADES A PARTIR DO BRASIL}

A criminologia comporta uma série de definições desde suas origens europeias, quando foi articulada e pensada pela primeira vez, até a recepção hegemônica por um país periférico desde sua origem (DEL OLMO, 2004), como o Brasil. 


\section{Humanos e}

Democracia

É indiscutível que aqui não seria o espaço mais apropriado para problematizar o curso de rupturas e permanências dos discursos deste saber. ${ }^{4}$ É importante compreender, porém, a origem do discurso criminológico e suas funções para, daí, identificar como se deu a recepção na América Latina e como é hoje atualizada. Não se olvida os arriscados saltos que serão realizados (OLIVEIRA, 2004), no entanto, por não se pretender realizar a história social das ideias, talvez se justifique.

De antemão é importante uma questão: Para que uma discussão que trata de sistema infracional está tratando do sistema punitivo?

Duas razões explicam. A primeira porque está a se indicar que a orientação teórica da pesquisa é a criminologia, cuja origem reside em demandas de ordem em contextos econômicos e sociais específicos (PAVARINI, 1983), logo, é indispensável falar de sistema punitivo. A segunda porque, aqui se parte da hipótese apresentada por Zaffaroni (2003) de que desde o nascimento do sistema punitivo no Brasil existem sistemas paralelos que atuam de forma não oficial de punição. Isto é, de um lado um sistema penal em sentido estrito, de outro um modelo paralelo, composto por agências de menor hierarquia, destinado a operar com uma punição tida como menor, razão pela qual gozaria de maior discricionariedade (arbitrariedade). Esse último é o sistema infracional.

Na verdade, "A história da infância é a história de seu controle" (GARCÍA MENDÉZ, 1991, p. 23) e nesse sentido, e mais, sendo as medidas socioeducativas formas de responsabilização, não se pode deixar de falar de um sistema penal. Dessa forma, é preciso afastar eufemismos, pois:

Quem foi privado de liberdade está preso. Então quais, quais seriam estes atos infracionais que podem até mesmo levar à prisão? Seriam atos infracionais ao regulamento da escola? Ao estatuto de um clube? A regras de etiqueta? Às ordens do pai e mãe? À arbitrariedade da polícia ou de outro agente, autoridade ou cidadão qualquer? Ao Código Civil? Parece que não é! (SÊDA, 1999, p. 16).

É indispensável, portanto, pensar como o sistema infracional, pautado na lógica do sistema punitivo, opera na realidade brasileira, especialmente quando o sistema de garantia de direitos humanos da Convenção dos Direitos da Criança e do Adolescente foi amplamente recepcionado na legislação local.

A hipótese aventada neste trabalho é que esse sistema paralelo, por meio de ações não institucionais (ilícitas), oculta o controle dos indesejados, a partir de uma sujeição criminal que, em si, no conceito de Michel Misse (1999), é um tipo social negativo que encarna um acúmulo histórico de uma lógica social. Neste momento, contudo, o importante é compreender a criminologia no Brasil para daí então discutir sobre qual criminologia (ANDRADE, 2008) está a se falar quando é utilizada como teoria de orientação metodológica para a pesquisa, exatamente porque existem criminologias no plural.

\footnotetext{
4 Um dos caminhos para se conhecer os discursos criminológicos está em Anitua (2008). Também tratando da mesma temática em Pavarini (1983).
} 


\subsection{O “Assombroso Transplante" e a Função de Contenção - Discurso Criminológico no Brasil}

A recepção da criminologia europeia na realidade marginal e periférica é definida por Bergalli (1983) como um "assombroso transplante", o que é curioso, posto que essa teoria tradicional definia a incapacidade moral dos países periféricos, justificando a inferioridade de seu povo desde a miscigenação até a indolência. Como e por que recepcionar um saber que inferiorizava o próprio povo, a ponto de Zaffaroni (1991) definir o positivismo como uma "gigantesca instituição de seqüestro"? E quais as consequências de uma leitura criminológica atualmente?

Os debates sobre o sistema punitivo, na análise europeia, centraram seus esforços entre o desenvolvimento do modo de produção capitalista e a pena privativa de liberdade (as funções latentes e declaradas são discutidas à luz do sistema econômico e político do capitalismo) que em si já eram reducionistas, não levando em consideração, por exemplo, o disciplinamento como fator configurador; como apontava Foucault (1977).

Se, na Europa, o grande encarceramento teve expansão na sociedade disciplinar com redes de prisões, manicômios, internatos e asilos para garantir o exército industrial de reserva, como garantir que esses mesmos objetivos se realizem numa cultura como a brasileira, em que o "jeito" - "uma instituição paralegal altamente cotada e conhecida" (ROSENN, 1998, p. 13) - é uma constante?

Aliás, Zaffaroni (2003) alerta sobre isso indicando que há elementos locais que não se adaptam às teorizações dos países centrais. Aqui não há efetivo controle das estruturas de poder, de modo que a imprevisibilidade e improvisação são questões costumeiras e visam a garantir que a ordem funcione e que são regras gerais das práticas institucionais.

Nesse sentido, a absorção das ideias foucaultianas não pode ser feita acriticamente, sobretudo quando o autor trabalha com os conceitos de sociedade disciplinar e docilização dos corpos para torná-los economicamente produtivos. Sim, porque além de o panóptico ter sido irrealizável na própria Europa, em que as prisões francesas de 1848 eram "'um sinistro espetáculo': comida podre, presos descalços arrastando-se em andrajos, pés ulcerados, pernas inchadas, rostos emagrecidos, tez pálida [...]", como aponta uma historiadora francesa (PERROT apud OLIVEIRA, 2011, p. 326) para criticar a normatividade de Foucault; não foi possível numa sociedade onde "o buraco da disciplina sempre foi mais embaixo" (OLIVEIRA, 2011, p. 323).

Camila Prando (2006, p. 80) é bem clara nesse sentido: "Se na Europa Ocidental a prisão tornou-se uma pena relacionada à disciplina das massas marginalizadas ao mercado de trabaIho capitalista, o mesmo não se pode falar da América Latina".

No Brasil, a sociedade é indisciplinar, como caracteriza Luciano Oliveira. Convive com exclusões morais, em que o adestramento das almas é substituído pelo "espancamento na rua ou no posto policial" e a masmorra é o princípio de tudo, forma "imediata e barata, qual seja, entulhar os exíguos espaços com o maior número possível de presos" (OLIVEIRA, 2011, p. 323).

E mais, "a idéia do panóptico não se aplicou aqui, porque não havia nem população carcerária para tal, já que a concentração de habitantes se encontrava no meio rural, nem mercado que necessitasse desse disciplinamento, uma vez que se estava ainda longe de uma possível Revolução Industrial latino-americana" (PRANDO, 2006, p. 86). 


\section{Democracia}

Além disso, o discurso do homem degenerado moralmente desenvolvido na Europa foi transportado para uma sociedade até então marcadamente rural, que, ao ingressar nos primeiros anos da República, convivia com uma realidade também marcada pela urbanidade em virtude do processo de industrialização. Esse novo modelo de organização social e econômica não substituiu o antigo modelo rural, calcado na grande propriedade; ao contrário, o processo de industrialização encontrou no desenvolvimento rural enormes possibilidades para se desenvolver.

Sim, porque no final do século 19 o Brasil era apontado pelos viajantes como um caso único e extremado de miscigenação racial. Um cruzamento que rendeu à população um estigma da deterioração, nas menções europeias, tornando-se, portanto, a questão racial um elemento determinante para os destinos da nação.

A hipótese que se lança é que a questão racial, assim, como a existência de raízes da violência, são as razões do sucesso das teorias raciais, chegadas tardiamente no Brasil (por volta da década de 70 do século 20), tendo sido profundamente acolhida pelos centros de pesquisa e ensino que, à época, congregavam a elite intelectual nacional (SCHWARCZ, 1993).

Quando se trata de compreender a realidade brasileira, no sentido de discutir o grau de influência da sociabilidade, da estrutura social, política, econômica e a própria gestação, enquanto povo, somente a Sociologia e a Antropologia podem auxiliar. Nesse sentido, considerando que "Nossa região marginal tem uma dinâmica que está condicionada por sua dependência e nosso controle social está a ela ligado" (ZAFFARONI, 1999, p. 66) e que, no Brasil, o Estado nunca consolidou o monopólio sobre a violência física e nunca conseguiu estatuir leis confiáveis, que mediassem as relações entre os indivíduos, o resultado foi que, em lugar de uma reversão das relações agressivas; o que existiu, ao longo de toda sua História, foi a persistência de valores que cultuam a força como alternativa amplamente utilizada entre a população para solucionar conflitos. A criminologia com brasilidade deve levar em conta essas estruturações da sociedade brasileira, e nesse contexto, a interdisciplinaridade é indispensável.

Neste sentido, Sozzo (2003) aponta que, para evitar novas dependências culturais, deve-se considerar, necessariamente, a realidade sociopolítica concreta do continente, o que esbarra num problema grave - a escassez de pesquisas empíricas na América Latina.

É por esta razão que a criminologia tem de crescer em pesquisas sobre a realidade, a fim de que possa se superar "a falsa disjuntiva" nas ciências criminais, e uma parceria entre criticismo e garantismo criminologicamente fundamentado - entendido como "vigilância sobre o (des)respeito aos direitos humanos no marco do funcionamento efetivo (deslegitimado) do sistema penal", seja de fato concretizado (ANDRADE, 2012, p. 99).

A incursão nessa problemática implica compreender os discursos jurídicos, cuja função política é objeto da criminologia (ANITUA, 2008), bem como a realidade na qual esse discurso é operado, especialmente quando se pretende conhecer a representação social ${ }^{5}$ do sujeito considerado suspeito. Esse conteúdo é trabalhado por instrumentais analíticos que escapam à criminologia, mas são, ao mesmo tempo, indispensáveis para a compreensão da realidade brasileira.

\footnotetext{
Representação é "algo que alguém nos conta sobre algum aspecto da vida social” (BECKER, 2009, p. 18), seja comum, elaborada nos atos mais simples da vida cotidiana, seja mais elaborada, preparada com preocupação de cientificidade. São informações que orientam as práticas e relações humanas, construídas por meio de comunicações sociais e apreendidas socialmente, além de variar em função dos extratos econômicos e culturais em que se inserem os indivíduos ou grupos (ANCHIETA; GALINKIN, 2005). As representações sociais funcionam como princípios orientadores e indutores de condutas seja de indivíduos, grupos ou instituições, de modo que compreender como a magistratura representa as medidas socioeducativas de internação importa desvendar o que se pensa sobre o instituto, captando seus significados, expondo seus sentidos (PORTO, 2006).
} 
É nesse momento que a abordagem da sujeição criminal de Misse pode e deve ser somada à compreensão criminológica. Sim, porque aponta ele - o acúmulo histórico de uma dada realidade pode levar a um tipo social negativo que será avaliado independentemente de sua conduta (MISSE, 1999).

Acredita-se que assim será possível chegar mais próximo da compreensão do real significando do discurso protetivo do adolescente no Brasil.

\section{3 "SUJEIÇÃO CRIMINAL": O ACÚMULO HISTÓRICO-SOCIAL BRASILEIRO E A AUTONOMIZAÇÃO DO RÓTULO - UMA EXPERIÊNCIA ETNOGRÁFICA}

O processo de acusação social assume uma dimensão ampla e violenta, principalmente na esfera pública, na qual funciona como dispositivo que determina o começo e o fim da construção social do crime e que perpassa o que Misse (1999) identifica como sujeição criminal.

Entende-se que a acusação social permite, nos termos das relações construídas na sociedade brasileira, a identificação e exposição de indivíduos que praticam supostas condutas indesejáveis. A acusação social, entretanto, assume proporções extremamente gravosas que, em determinadas situações, não interessa se de fato tenham sido praticadas. Ou seja, o direcionamento de instrumentos formais e informais de dominação e controle passa a ser direcionados aos aspectos subjetivos do indivíduo.

Segundo Michel Misse (2008, p. 15), quando a ênfase recai sobre a transgressão, e não sobre o sujeito transgressor, há uma minimização entre o fato e a lei a ser aplicada, ou seja, o processo de subsunção entre essas duas esferas passa a ocorrer com a separação entre as leis, códigos éticos e morais e os elementos subjetivos que compõem o indivíduo.

A racionalidade adotada pelas instituições de controle formal e informal, todavia, vem sendo instrumentalizada com base em outros aspectos, pois na modernidade se busca instrumentalizar meios para identificar no transgressor justificativas para a conduta praticada (MISSE, 1998).

Ocorre que, diante dos padrões de criminalidade e violência vivenciados no Brasil, ontem e hoje, busca-se racionalizar o tipo criminoso, independentemente de qualquer prática delituosa, justificando, não pela prática da transgressão, mas pela possibilidade de transgredir.

Nesse sentido, o direcionamento de estruturas de controle e suspeição é voltado para aspectos subjetivos, como determinados padrões de postura do indivíduo, localidade em que se encontra, padrões étnicos, culturais e morais vivenciados por ele. Tudo transformado em acusações sociais. Ou seja, o tipo criminoso independe da prática de qualquer transgressão legal, basta ser identificado como suspeito. Conforme segue:

Na modernidade, com a ênfase posta na racionalidade da ação e no autocontrole, as nuances apontam principalmente para um sujeito, fazendo dele e de sua subjetividade o ponto de ancoragem da acusação. Constituem-se diferentes tipos sociais segundo a regularidade esperada de que indivíduos sigam variados cursos de ação reprováveis (MISSE, 2008, p. 15).

Dessa forma, a dimensão externa da acusação social termina por legitimar especulações criminosas com base exclusivamente em aspectos subjetivos que cercam determinados indivíduos, por se encaixarem no que Misse (2014) denomina de tipos sociais negativos. Assim, é 


\section{Democracia}

possível ter-se uma dinâmica violenta de exposições, com a possibilidade de morte, na qual inúmeros atos violentos são justificados contra esses indivíduos, com base exclusivamente em elementos subjetivos, construídos como negativos, a partir de paradigmas históricos determinados por grupos hegemônicos.

Os dados e acontecimentos de repercussão nacional demonstram essa conclusão. As vítimas de homicídios praticados pela polícia no Rio de Janeiro são negros e jovens entre 15 e 24 anos, moradores das localizações periféricas da cidade, como se percebe no quadro da Anistia Internacional (2015).

Gráfico 1 - Homicídios docorrentes de intervenção policial, por sexo, na cidade do Rio de Janeiro, entre 2010 e 2013

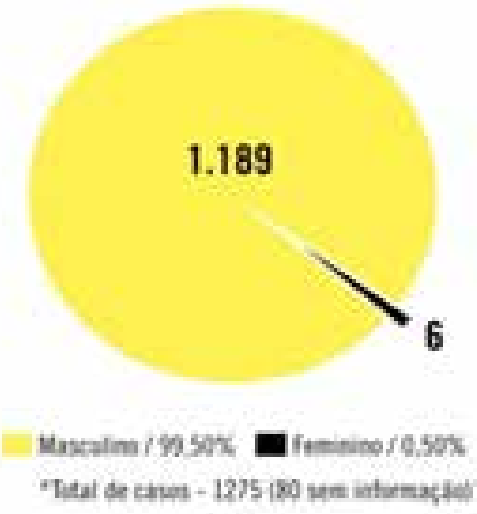

Gráfico 2 - Homicídios docorrentes de intervenção policial, por raça/cor, na cidade do Rio de Janeiro, entre 2010 e 2013

Fonte: Elaboração própria baseada em dados do Instituto de Segurança Pública e Secretaria de Segurança Pública do Rio de Janeiro (FBSP, 2014).

Esse cenário é repetido nos dados sobre as mortes violentas intencionais em todo o país. O Anuário Brasileiro de Segurança Pública de 2014 aponta o crescimento da vitimação juvenil, chegando a representar, com os dados de 2012, 53,4\% dos homicídios ocorridos (FBSP, 2014).

Gráfico 3 - Participação (\%) dos homicídios juvenis no total de homicídios. Brasil 1980/2012

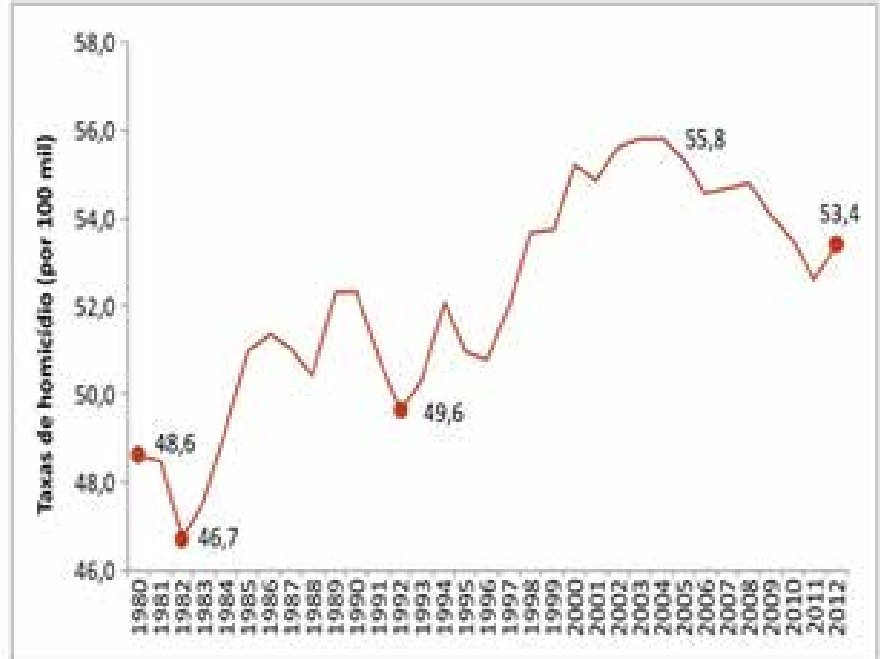

Fonte: SIM/SVS/MS 
A evidência de que a vida do jovem negro e da periferia é descartável é ainda mais evidente nesse quadro (FBSP, 2014).

É possível perceber, portanto, o extenso número de mortes com autorização social de uma população que

muito além do descaso histórico em relação à precariedade das condições de vida e da indiferença social, essas populações sofreram toda sorte de violência, em especial a física, perpetrada pelos muros da internação e pela arbitrariedade policial materializada sob a forma de tortura e maus tratos que por vezes terminam em morte (VARGAS, 2011, p. 30).

O que se observa, na verdade, são construções baseadas em particulares (privado) que se estendem ao público e determinam o modus operandi de suas instituições. Essas construções, baseadas em um tipo social negativo tornam-se externas a partir do processo de acusação social e que vem reverberar na sujeição criminal desses tipos sociais negativos.

Gráfico 4 - Taxas de homicídio branco e negro e vitimização negra. População total. Brasil 2002/2012

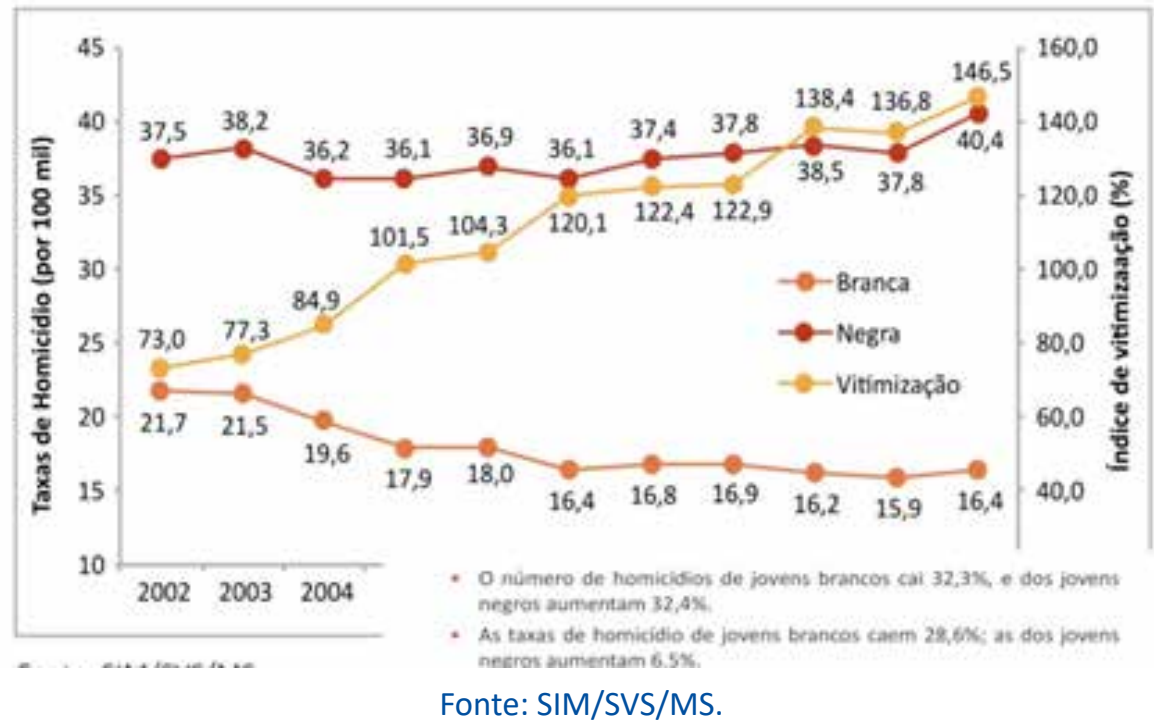

A ideia de Misse, ao relacionar a perspectiva interacionista de Becker com a abordagem macrointeracionista, resultou na ferramenta interpretativa de que o rótulo não está necessariamente atribuído a uma prática, pois esse não se "descola" do indivíduo após a condenação (TEIXEIRA, 2011, p. 171), mas ao revés, a força do rótulo de criminoso é naturalizada e a sujeição criminal é um dispositivo de criminalização autônomo, pois, na realidade brasileira, a sobreposição estamental (desde o escravagismo até o individualismo) e a ordem hierárquica (garantida pela violência desde suas raízes) fazem com que seja um "processo social que conduz a determinadas prática sob uma classificação social, relativamente estável, enquanto tal, legítima (MISSE, 1999, p. 67).

Nesse sentido, o que tem sido observado é que com a identificação do suspeito, a acusação social não precisa ser externalizada para legitimar a violência repressiva de dispositivos de controle formais e informais. Ao que parece, existe um consenso interno e coletivo que direciona a acusação social, sem que ela precise ser externalizada. 


\section{Democracia}

É o que pode ser observado em alguns relatos de policiais militares coletados junto a Gerência de Polícia da Criança e Adolescente (GPCA), localizada na cidade do Recife/PE, a seguir analisados.

\subsection{Uma Experiência Etnográfica na Cidade do Recife - A Concretização da Sujeição Criminal}

Nesta pesquisa a abordagem da realidade visa a compreender o discurso das polícias no âmbito do sistema infracional, razão pela qual serão abordados alguns elementos de experiência etnográfica ${ }^{6}$ realizada na cidade do Recife, no período de 2 de junho de 2015 a 30 de setembro de 2015.

Além disso, foram realizadas entrevistas em profundidade com policiais da localidade, com o fim de obter mais detalhes sobre a representação social desses agentes sobre suas práticas em relação ao adolescente considerado suspeito.

A orientação teórica foi imprescindível porque baliza a pesquisa para evitar meras descrições de um fenômeno de uma cultura, com afirmações de um tipo popularesco, estilo jornalístico (BECKER, 2007, p. 40). É neste sentido que a interpretação dos dados será realizada à luz dos marcos teóricos já referidos.

O método utilizado para a realização da pesquisa foi o da observação não participante, que permitiu a compatibilização entre a praxe adotada pelos agentes policiais, que não admitiam qualquer tipo de interferência no momento de formalização do flagrante, e os anseios dos pesquisadores em estar presentes nesse procedimento, com o receio de ensejar intimidações dos agentes policiais no ato observado

Tendo como objeto o fenômeno antropológico, a presente pesquisa não poderia se desvirtuar dessa abordagem, razão pela qual houve a preocupação do estudo do diferente, de presenciar algo que se mostre tão incomum e estranho que só possa ser vislumbrado como uma roupagem do "outro". Nesse sentido, Rodrigues destaca que:

Apesar do crescente acesso ao sistema de justiça, tem-se que devido à complexidade de sua composição, com diversas instituições, instâncias, códigos, ritos, procedimentos, solenidades, autoridades, textos e simbolismos, a compreensão de seu funcionamento ainda não se mostra inteligível e acessível para quem observa de fora (2010, p. 306).

Desse modo, a indicação de que o pesquisador deve se manter afastado do objeto pesquisado com o intuito de não comprometer a parcialidade, foi objetivo almejado em todo o transcurso da pesquisa, pois a observação etnográfica tem como importância fundamental possibilitar reflexões sobre as condições em que se produz o conhecimento antropológico e social.

Assim, é um modo de construir um conhecimento sobre uma realidade social já construída. De tal maneira, ela (a realidade) é também um instrumento de percepção do estranho e das exceções, pois, tratando-se da esfera social, nenhum comportamento humano é passível de ser absolutamente determinado.

\footnotetext{
Trata-se de recorte de pesquisa de dissertação de Mestrado que o segundo autor está realizando no programa de Pós-Graduação em Direito da Universidade Católica de Pernambuco, sob orientação de Luciano Oliveira e coorientação da primeira autora.
} 
Neste tópico, pede-se permissão para assumir a primeira pessoa verbal, em virtude do protagonismo da etnografia.

No dia 4 de setembro de 2015, já passava das 18 horas quando me direcionei para fora da delegacia, enquanto esperava o término da oitiva de dois policiais e duas adolescentes acusadas de "quebrarem" e agredirem dois agentes de defesa social no Case Santa Luzia, ${ }^{7}$ Diante de uma situação que parecia, na verdade, uma "bronca" entre pais e filhas por mau comportamento e que resultaria no drástico "castigo" do recolhimento ao sistema de internação provisório, conhecido como Cenip ${ }^{8}$ resolvi sair da delegacia.

Ao me direcionar para fora da GPCA, tive a oportunidade de entrevistar o cabo Tenório, ${ }^{9}$ pertencente ao batalhão da Rocam, ${ }^{10}$ e que devido aos seus vários anos de polícia, estava pleiteando aposentaria. No momento da conversa ele aguardava ser ouvido sobre o caso de uma agressão física advinda de dois adolescentes que teriam se desentendido na sala de aula de uma escola pública, e as diretoras da instituição acharam por bem chamar a polícia. Após me apresentar e explicar o motivo das perguntas, a conversa se deu nos seguintes termos:

P: Como são feitas as abordagens?

CTT: Geralmente a abordagem é feita mais ou menos em torno de bairros suspeitos, 0 camarada tá com uma bolsa, uma mochila, naquele setor.

P: Setores de bairro... se eu pudesse mapear ali e colocar os bairros considerados "suspeitos".

CT: São vários: Santo Amaro, Coque, os Coelhos, embora os coelhos quebrou muito, os Coelhos é hoje $20 \%$ do que era, Brum...favela do Brum. ${ }^{11}$

P: E caso, tá na rua fazendo ronda, em determinada localidade e vou abordar aquele, o que faz vocês abordarem aquele? O que faz levar a abordar aquele determinado adolescente ou coisa assim?

CT: Não, adolescente é se ele tiver em atitude suspeita, né? Porque se ele tiver fazendo coisa errada, ele fica meio receoso quando vê polícia, né? Aí se ele apresentar certo nervosismo ou alguma coisa, acho melhor abordar...

P: Nervosismo da pessoa né?

CT: Nervosismo, o trejeito dele (Recife, 4/9/2015)

Centro de Atendimento Socioeducativo - Santa Luzia, unidade de execução de medida de internação de adolescentes do sexo feminino.

8 Centro de Internação Provisória.

9 Nome fictício e baseado na música "Cabo Tenório" composta por Rosil Cavalcanti e Jackson do Pandeiro em 1954. A música narra a história de um militar benquisto pela sociedade e por seu batalhão por resolver os conflitos que emergiam na região em que era lotado. O cabo fazia um tipo "valentão", mas que vibrava e se acalmava ao ser reconhecido pela sociedade como o maior inspetor do quart

${ }^{10}$ Ronda Ostensiva com Apoio de Motocicleta, unidade da Polícia Militar de Pernambuco.

${ }^{11}$ Todos os bairros são periferias da cidade do Recife. 


\section{Democracia}

Observa-se nesse pequeno trecho como o discurso de um agente que atua há mais de 20 anos no sistema de justiça criminal é orientado pelo olhar de um tipo social negativo e que reverbera na sujeição criminal, legitimando uma desconfiança em relação a atos banais, como portar uma mochila e morar em locais específicos.

Além disso, o nível de pobreza é decisivo na caracterização do adolescente suspeito.

Dependendo de como se estabeleça a relação entre sujeição criminal e distância social, podem evidenciar-se importantes ambivalências na avaliação local do transgressor, como de outra parte, podem se alargar extensões sociais da sujeição criminal que compreendam famílias inteiras, ruas favelas, bairros ou parte inteira de uma cidade (Misse, 2008, p. 24).

Michel Misse (2008, p. 22) ao direcionar sua análise sobre as relações e construções tipológicas que permeiam nossa sociedade, entende que as relações intersociais presentes nos domínios sociais que constituem as estruturas da sociedade brasileira, inclusive o processo de subversão entre essas categorias como a casa pela rua e o público pelo privado, podem ser entendidas a partir do que ele chama de distância social.

Dessa forma, é por meio do processo de subversão de interesses e posturas dominantes de determinados grupos que se sobrepõe sobre outros. Recorre-se, inclusive, ao processo de criminalização desses indivíduos e grupos, direcionando o maquinário das instituições de Justiça Criminal. Misse (2008, p. 22) enfatiza que a distância social determina, com base em estruturas morais, aquilo que seria o principal eixo do processo de normalização e consequentemente de direcionamento de formas de controle de subjetividades e relações sociais.

Distância social desregulada e práticas crimináveis recorrentes constituirão, por sua vez, o principal núcleo da mobilização para a incriminação dos indivíduos acusados e para a constituição da sujeição criminal na modernidade. A autodemanda subjetiva de incriminação torna plenamente justificável, de um ponto de vista público, a mobilização interna para efetua a denúncia, diferentemente do que se passa entre atores que partilham um mesmo ambiente privado, ou de vizinhança, onde outros fatores podem intervir para atenuar ou modificar essa mobilização (MISSE, 2008, p. 23).

Dessa forma, a distância social atua como um verdadeiro medidor que pode ser analisado a partir de duas perspectivas: primeiramente como um instrumento de seletividade entre indivíduos que ao se aproximarem em uma dimensão moral e de poder se reconhecem como pertencentes ao mesmo processo civilizatório e de normalização, tal qual ocorre no domínio privado, e suas relações presentes no interior da casa. Na medida, entretanto, em que essa distância social vai se maximizando, os laços e hierarquias vão se tornando distantes, a ponto de indivíduos serem subjugados como pertencentes a dimensões morais e civilizatórias 
diferentes. Ou seja, a repulsa do outro presente na rua, ${ }^{12}$ um domínio onde os laços fracos e duvidosos entre desconhecidos preenchem aquele espaço e os marcam com o processo de sujeição criminal.

Mas antes de ser apenas cultural a distância social é um indicador de como se pratica, se opera e se representam as relações de poder numa determinada sociedade. Ora, a construção da civilidade burguesa e a normalização do individualismo deram-se principalmente pela regulação da distância social entre os indivíduos e classes, impedindo-a que diminuísse muito (no caso interindividual, principalmente na esfera privada e no espaço íntimo, onde afetos e paixões têm livre curso) ou aumentasse demais (principalmente na esfera pública, que regula os interesses entre as classes) (MISSE, 2008, p. 22).

Ademais, a distância social por meio da soma de inúmeros elementos condicionantes que vão além da moral, e que carrega uma carga histórica do processo de formação da sociedade brasileira, além de definir quem são os indivíduos, grupos ou até mesmo comunidades que passam pelo processo de sujeição criminal (MISSE, 2014), também determina o paradigma normalizador e civilizatório da sociedade brasileira, a partir de aspectos subjetivos, como padrões morais, culturais, políticos e econômicos de grupos hegemônicos. Nesse sentido, enfatiza Michel Misse (2008, p. 23) que a distância social a partir de determinados parâmetros transfere para a subjetividade do agressor mediante o que ele chama de "acusação social" aquilo que deveria ser restrito ao ato transgressor.

Dessa forma, esse processo de subversão permite que interesses e posturas de classes dominantes, não só no âmbito econômico, mas em uma esfera muito mais ampla, na qual se dita os aspectos morais, civilizatórios, estenda-se ao universo público, de modo que certos paradigmas comuns a uma classe hegemônica e que seriam restritos ao âmbito privado se estendam à esfera pública. Nesse processo acusatório e baseado em construções fundadas em paradigmas hegemônicos, surge a figura do suspeito, muitas vezes construído contra indivíduos e grupos que não possuem qualquer laço direto ou indireto com a criminalidade.

São indivíduos cujos atos mais simples e comuns são verdadeiros pontos de acusação. $\mathrm{E}$, ao que parece, a própria polícia atribui, como fundamento para essa violência seletiva, determinada incivilidade e/ou periculosidade como elementos que justifiquem a ação repressiva, conforme segue:

Na modernidade, a acusação se emancipa da transgressão (que se torna no mínimo moralmente ambivalente ou duvidosa) para se dirigir à subjetividade do transgressor, à sua desnormalização, à sua incivilidade, às suas "fraquezas". Ao investir no acusado uma posição de fraqueza (moral, social, de caráter), aumenta-se o investimento de poder do acusador (MISSE, 2008, p. 17).

\footnotetext{
12 Casa e Rua são categorias de Roberto DaMatta (1997) utilizadas por Misse que a perpetuação de espaços que predominam como lugares de características e atividades específicas. Tais categorias sociais são dotadas de determinadas características que refletem e reverberam uma série de aspectos que permeiam a sociedade e seus fenômenos, seja em um âmbito mais reservado, privado e marcado por uma série de hierarquias, como é o domínio da casa onde moralidades e identidades de um determinado grupo de indivíduos preenchem aquele lugar, ou em uma esfera mais ampla, onde as hierarquias não se encontram tão definidas, em que a ausência de laços e a presença do medo do desconhecido fazem emergir a figura do "outro", impingindo o distanciamento e a ausência de identidade, marcando as relações entre os indivíduos que transitam ou permanecem naquela esfera, como é o domínio da rua.
} 


\section{Humanos e \\ Democracia}

O que parece como mais perigoso é o teor de cientificidade que é dado por meio da racionalização desse processo de sujeição criminal. As estruturas de controle do Estado, por intermédio das suas legislações e outros códigos normativos, camuflam, sob o manto da neutralidade e legitimidade, uma série de construções seletivas e de teor extremamente violento. Conforme afirma Misse (2008, p. 17), "cabe à lei oferecer legitimidade a um processo que, de outro modo, padeceria de "neutralidade".

Segue a entrevista:

P: O trejeito? Isso é só a experiência que diz?

CT: É... mas a formação da gente faz com que a gente aborde também. A formação da gente ensina isso aí.

$P$ : Nessa formação, eles ensinam o quê?

CT: Ensinam a abordar, né? Mas quem vai decidir quem abordar é a gente na rua.

CT: Dois caras de moto passando, atitude suspeita. Dois, três elementos de carro perturbando... tipo assim. A cidade em si, aqui da gente, faz com que a gente aborde muito por causa disso, a violência é grande, tráfico grande, mas se fosse em outro local, numa cidade que não tem tanto, tipo Santa Catarina, Blumenau, que é uma cidade que não tem tanta violência como aqui. Aí a situação de abordagem é outra, mas aqui... a população vive com o nervo à flor da pele, leva a gente a abordar... porque se a gente não procura a gente não acha.

Metrô... tá tendo esses assaltos todinho, geralmente é em três, aí a gente vai separando aquele ali, pq tá acontecendo esse tipo de assalto.

P: tipo, questão de roupa a gente vê repetição nos trajes, né?

CT: em si, o pessoal daqui, a gente mais ou menos vê o tipo de roupa, mas a roupa hoje em dia não quer dizer nada... o tipo de roupa, o que vai dizer é o tipo do camarada (Recife, 4/9/2015).

O que se observa na fala do cabo é a instrumentalização de uma construção social do indivíduo identificado como criminoso. Esse tipo social negativo, dotado de periculosidade e de um intenso caráter criminógeno, é racionalizado e instrumentalizado pela própria Academia de Polícia, nos seus cursos de formação de agentes policiais. ${ }^{13}$ Ora, ao que parece, a própria polícia legitima a seletividade e mostra que ela precisa representar a verdadeira violência no Brasil.

Acrescenta-se a isso o estoque ancestral de imagens lombrosianas que a polícia acumulou ao longo dos anos: os sujeitos "manjados" (e sua generalização para outros tipos bociais), que a polícia pensa que conhece e que, portanto, pode incriminar por "antecipação" (MISSE, 2008, p. 24).

\footnotetext{
13 "O tipo de formação institucional que os policiais militares e civis recebem é de caráter repressivo, dogmático e instrucional, seja porque ligado ao direito punitivo, seja porque inspirado na formação militar" (KANT DE LIMA, 2013, p. 76). É no período da formação policial que os futuros policiais passam a se comprometer com a atividade a ser desenvolvida, visto que passam a compartilhar valores, crenças e habilidades uns com os outros, desenvolvendo, desta forma, sua identidade profissional (KANT DE LIMA, 2014, p. 475).
} 
Esse processo de naturalização e racionalização do tipo criminoso é tão intensa que assustaram o pesquisador a calma e a naturalidade da fala do cabo Tenório. Para ele, a repetição desse tipo construído como negativo e perigoso, ao longo dos seus mais de 20 anos de atividade como militar, não passa de uma equação matemática para a identificação do criminoso, em que a soma de fatores como pobreza, favela, idade e raça resultam na figura do indivíduo suspeito. Uma fórmula histórica e, ao que parece, na visão das instituições de Justiça Criminal, não tem como dar errado.

Enfim, o que interessa para a presente exposição é que, a partir dessa extensão e subversão entre os domínios da casa e da rua, padrões de comportamento e determinadas características como estereótipos e de desvios, são identificados pelo olhar de quem assume o domínio sobre determinados grupos, mediante relações de poder e controle.

Dessa forma, a construção social, que precede a identificação de indivíduos, posteriormente estereotipados como desviantes ou suspeitos, passa necessariamente pela concepção já solidificada de um olhar hegemônico que identifica aquele indivíduo ou grupo como um tipo social negativo, nos termos de Michel Misse (2008). Esse processo que marca a seletividade de indivíduos como propensos a cometer um crime é exatamente a sujeição criminal.

A sujeição criminal através da qual são selecionados preventivamente os supostos sujeitos que irão compor um tipo social cujo caráter é socialmente considerado "propenso a cometer um crime". Atravessando todos esses níveis, a construção do crime começa e termina com base em algum tipo de acusação social (MISSE, 2008, p. 14).

Observa-se que a sujeição criminal se repete nas inúmeras esferas sociais brasileiras, desde o processo de educação de uma criança em seu núcleo familiar à execução e modus operandi de um sistema de Justiça, como o criminal. Tais consequências repetem-se no processo de formação do Estado e do processo civilizatório brasileiro, inclusive recorrendo a elementos de criminalização secundária, que acabam justificando o direcionamento de uma série de mecanismos de exclusão e controle contra esses grupos:

O país que no ano dois mil completou meio milênio é uma nação de constrastes sociais e econômicos que podem ser explicado à luz do seu passado de exclusão de negros, índios, e idéias politicamente deletérias para a ordem do patriarcado, na Colônia ou no Império. A exclusão e subordinação social, econômica e política de raças e ideários não hegemônicos são raízes fincadas na fundação da civilização brasileira e parecem, hoje, constituir a natureza da mesma do Estado (NUMERIANO, 2000, p. 83).

Considerando o cenário apresentado, é importante, pois, ponderar sobre a função e o real papel da Doutrina Integral, pois uma pergunta não pode ser desconsiderada: Por que essas práticas de violação de direitos ainda permanecem, com a mudança de paradigma?

\section{O DISCURSO JURÍDICO (PROTEÇÃO INTEGRAL) E A NORMALIZAÇÃO DA JUVENTUDE: A REIFICAÇÃO DO ADOLESCENTE SUSPEITO}

A sociedade brasileira é dotada de inúmeros domínios e categorias sociais que se completam, e, muitas vezes, assumem perspectivas opostas, ressaltando as inúmeras relações e eventos sociais que constituem o dinamismo do processo histórico de formação. 


\section{Humanos e \\ Democracia}

Diante de tal complexidade, estudiosos, notadamente historiadores, sociólogos e antropólogos, traçaram análises acerca das categorias sociais presentes nessa rede complexa de estruturas como forma de entender determinados fenômenos que formam aquilo que se chama de sociedade. Ou seja, a necessidade de se analisar e entender, a partir de uma perspectiva local (DAMATTA, 1982), os inúmeros acontecimentos que reverberam no processo de construção social.

Nesse sentido, os próprios criminólogos brasileiros vêm recorrendo à Sociologia e Antropologia Social, voltando-se cada vez mais para a necessidade de se estudar os fenômenos da criminalidade e da violência a partir dos elementos e particularidades que constituem nossos fenômenos locais. Ou seja, a necessidade de uma análise "abrasileirada", de modo a não se limitar a comprimir e aplicar teorias e conceitos advindos de contextos que abarquem construções sociais, culturais, econômicas e políticas completamente dissonantes, ou que passem uma visão míope dos fenômenos como a criminalidade e do sistema de justiça brasileiro, inclusive com base em elementos que reverberam efeitos na estrutura social do país (OLIVEIRA, 2011; ANDRADE, 2012).

O processo de formação de uma sociedade muitas vezes passa por inúmeras rupturas e mudanças, tanto nas estruturas estatais como no habitus da própria sociedade em si, e daí algumas categorias se repetem e solidificam suas funções que se perpetuam no Brasil, no conturbado processo de formação dos centros urbanos.

Aqui discutiu-se a necessidade de a criminologia valer-se de conceitos sociológicos, posto que diversas categorias de análise reverberam efeitos no direcionamento de mecanismos disciplinares e de controle sobre os corpos de indivíduos, cuja construção social representa um tipo social negativo, nos termos de Michel Misse (1999), em que a representatividade do medo e da violência tornam-se inerentes à subjetividade desses adolescentes.

Nesse contexto, é que se pretendeu entender, a partir de elementos que carregam determinada carga histórica e estrutural da sociedade brasileira, como esses domínios sociais constituem o background que reflete a construção desse adolescente suspeito.

O adolescente, como âmbito específico de intervenção estatal, na perspectiva da Doutrina da Proteção Integral, tornou-se sujeito de direito, no entanto a dinâmica desse significado, na realidade brasileira, marcada pela violência de todas as ordens, não correspondeu à construção universal da infância, como pretendiam os documentos internacionais.

Na verdade, a DPI categorizou duas infâncias - a destinatária de medidas protetivas em perigo, e as destinatárias de socioeducação - perigosas ( $\mathrm{SCHUCH}, 2005)$. Na medida em que houve a especialização das políticas, acentuou-se a intervenção sobre aquele considerado perigoso, não somente devido à perspectiva individualista, mas porque essa, na lógica do acúmulo social, na categorização de Misse (1999), é o alvo das demandas sociais por segurança. 
$\mathrm{Na}$ condição de categoria histórica que se acumula ao longo do tempo, o menor, além de estar associado ao abandono e à infração, soma-se à perspectiva social do aumento da violência que marca a década de 90 em diante na sociedade brasileira. ${ }^{14}$ Há um imaginário social sobre o bandido, o desviante, o delinquente, que além de povoar o submundo do crime é associado à pobreza urbana e ao tráfico. Essas figuras desnormalizadoras abrem "caminho para a construção do fantasma mais persistente da modernidade, o que interliga pobreza urbana, pauperismo e falta de alternativas regulares de mobilidade social ascendente ao incremento da opção criminal, em casos individuais, ou da revolta ou polícia em caso de ação coletiva" (MISSE, 1999, p. 47).

Logo, o conjunto desses conteúdos (menor) encapsulados na nova categoria "adolescente em conflito com a lei", traz consigo a demanda por controles para que esse sujeito não se amplie, que seja isolado, demarcado para não circular com outras pessoas que não têm o mesmo tipo social, afinal, sob essa concepção existe uma ligação subjetiva entre o sujeito e a transgressão. Há, então, uma expectativa social, a partir da subjetividade e da posição social, que pessoas identificadas com aqueles conteúdos não circulem.

No limite, são pessoas incrimináveis que possuem

signos corporais que comunicam uma "suspeita" de sua sujeição - sinais de perigo social - signos que contextualizam idade, gênero e cor com sinais de sua classe social (ou "subclasse"), educação, descontrole moral, uso de convenções sociais, além de símbolos negativamente interpretados, como certos tipos de tatuagens, de cicatrizes, cortes de cabelo, de gestos e modos de andar, de olhar, de conversar, de se vestir, tipos sociais e incriminação individual se intercambiam ou se complementam em várias áreas, produzindo com o tempo tipos sociais de sujeição criminal historicamente fixados (MISSE, 1999, p. 48).

A partir da definição, dá-se a incorporação da identidade social negativa e sua consequente acomodação a um tipo social. Ao tornar-se "menor", adolescente em conflito com a lei, numa nova estruturação com a Doutrina da Proteção Integral, mas meramente linguística, porque acumula o conteúdo social daquele operador inicial, a menina ou o menino não consegue mais escapar dessa identidade, mesmo que a recusando.

Se assim o é, as violências são justificadas porque, como sempre se identificou na história do país - há pessoas mais torturáveis que outras (OLIVEIRA, 2009). Nesse contexto de proteção integral, contudo, o alerta de Agostino Ramalho - "Quem nos salva da bondade dos bons" - é mais do que nunca indispensável. Jacinto Coutinho trabalha esta ideia de forma magistral, cuja transcrição se justifica:

\footnotetext{
${ }_{14}$ Na década de 80, o influxo de crimes violentos foi ascendente. Alba Zaluar (1989) mapeou que entre 1980-1991 foram vitimados 722 jovens de 13 a 25 anos em Cidade de Deus, conjunto habitacional popular no Rio de Janeiro, na "guerra perversa" contra as drogas. Em São Paulo, a PM matou 1.140 civis em confronto policial em 1991, enquanto em Nova York, onde as taxas de criminalidade violenta são elevadas, foram feridos 20 civis e vitimados 27 (ADORNO, 1994). Em 1992 a Polícia Militar atingiu seu ápice neste Estado, abatendo 1.359 pessoas (ADORNO, 1999). Ainda em São Paulo, crimes contra a pessoa e a propriedade na Região Metropolitana ocuparam mais de $50 \%$ dos registros policiais desde o início de 80 , correspondendo a 2.339 crimes contra a propriedade/cem mil habitantes em 1994 e 819 crimes contra a pessoa/cem mil habitantes no mesmo ano, crescendo mais do que crimes não violentos na mesma época (CALDEIRA, 2000).
} 


\section{Democracia}

[...] Afinal, com uma base de sustentação tão débil, é sintomático prevalecer a "bondade" do órgão julgador. O problema é saber, simplesmente, qual é o seu critério, ou seja, o que é a "bondade" para ele. Um nazista tinha por decisão boa ordenar a morde de inocentes; e neste diapasão os exemplos multiplicam-se. Em um lugar tão vago, por outro lado, aparecem facilmente os conhecidos "justiceiros" sempre lotados de "bondade", em geral, querendo o "bem" dos condenados, e antes, o da sociedade. Em realidade, há aí, puro narcisismo; gente lutando contra seus próprios fantasmas. Nada garante então, que a "sua bondade" responde à exigência de legitimidade que deve fluir do interesse da maioria. Neste momento, por mais elementar, é possível indagar, também aqui, dependendo da hipótese, "quem nos salva da bondade dos bons?", na feliz conclusão, algures, de Agostinho Ramalho Marque Neto (COUTINHO, 2002, p. 188).

Enfim, as violências são recorrentes e se dão em função da proteção prometida com a Doutrina da Proteção Integral. Um claro discurso que confirma o alerta de Agostinho Ramalho e um tema imbricado para a criminologia à la brasileira, na medida em que pretende atualizar a produção de saberes no âmbito da infância e juventude, evitando a classificação de infâncias ante o paradigma universalizado.

\section{REFERÊNCIAS}

ADORNO, Sérgio. Insegurança versus direitos humanos. Entre a lei e a ordem. Tempo Social; Rev. Sociol. USP, São Paulo, 11(2), p. 129-153, out. 1999.

ADORNO, Sérgio. Violência, controle social e cidadania: dilemas da Administração da Justiça Criminal no Brasil. Revista Crítica de Ciências Sociais, n. 4, 1p. 101-127, dez. 1994.

ANCHIETA, Vânia Cristine Cavalcante; GALINKIN, Ana Lúcia. Policiais Civis: representando a violência. Psicologia \& Sociedade, n. 17(1), p. 17-28, jan./abr. 2005.

ANDRADE, Vera Regina Pereira de. Pelas mãos da criminologia. O controle penal para além da (des)ilusão. Rio de Janeiro: Revan, 2012.

ANDRADE, Vera Regina Cavalcante. Por que a criminologia (e qual criminologia) é importante no ensino jurídico? Revista Eletrônica de Ciências Jurídicas. RECJ. 5.5/2008. Disponível em: www.pgj.ma.gov.br/ampem/ampem1. asp.

ANISTIA INTERNACIONAL. Você matou meu filho. Homicídios cometidos pela polícia militar na cidade do Rio de Janeiro. Rio de Janeiro: Anistia Internacional, 2015.

ANITUA, Gabriel Ignácio. História dos pensamentos criminológicos. Rio de Janeiro: Revan, 2008.

ANIYAR DE CASTRO, Lola. El debate sobre la criminología latinoamericana: un debate sin "punto final". In: Democracia y justicia penal. Caracas: Ediciones del Congreso de la República, 1992.

BECKER, Howard S. Falando da sociedade. Ensaios sobre as diferentes maneiras de representar o social. Rio de Janeiro: Zahar, 2009.

BECKER, Howard S. Segredos e truques da pesquisa. Rio de Janeiro: Zahar, 2007.

BERGALLI, Roberto et al. El Pensamiento Crítico y la Criminología: el pensamiento cirminológico. Bogotá: Temis, 1983.

CALDEIRA, Teresa Pires do Rio. Cidade de muros. Crime, segregação e cidadania em São Paulo. São Paulo: Ed. 34; Edusp, 2000.

COUTINHO, Jacinto Nelson de Miranda. Glosas ao "Verdade, Dúvida e Certeza" de Francisco Carnelutti, para os operadores do Direito. In: SÁNCHEZ RÚBIO, David et al. (org.). Anuário ibero-americano de direitos humanos (2001-2002). Rio de Janeiro: Lumen Juris, 2002.

CNJ. Conselho Nacional de Justiça. Censo do Poder Judiciário. Vide - Vetores Iniciais e Dados Estatísticos. Brasília: CNJ, 2014.

DAMATTA, Roberto. A casa e a rua. 5. ed. Rio de Janeiro: Rocco, 1997.

DEL OLMO, Rosa. América Latina e sua Criminologia. Rio de Janeiro: Revan, 2004.

DEL OLMO, Rosa. Criminología y derecho penal: aspectos gnoseológicos de una relación necesaria en la América Latina actual. Doctrina Penal, Buenos Aires, ano 10, n. 37, p. 75-96, 1987. 
DE PAULA, Liana. Da "questão do menor" à garantia de direitos. Discursos e práticas sobre o envolvimento de adolescentes com a criminalidade urbana. Civitas, Porto Alegre, v. 15, n. 1, p. 27-43, jan./mar. 2015.

FBPS. FÓRUM BRASILEIRO DE SEGURANÇA PÚBLICA . 8 anuário brasileiro de segurança pública. São Paulo: FBPS, 2014.

FÓRUM BRASILEIRO DE SEGURANÇA PÚBLICA. Anuário Brasileiro de Segurança Pública. São Paulo, 2014.

FOUCAULT, Michel. Vigiar e punir. Petrópoles: Vozes, 1977.

GARCÍA MÉNDEZ, Emílio. In: CURY, Munir; AMARAL E SILVA, Antônio Fernando; GARCíA MENDEZ, Emílio (orgs.). Estatuto da Criança e do Adolescente comentado. Comentários Jurídicos sociais. São Paulo: Malheiros, 1991.

KANT DE LIMA, Roberto. Éticas e práticas na segurança pública e na justiça criminal. In: LIMA, Renato Sérgio de; RATTON, José Luiz; AZEVEDO, Rodrigo Ghiringhelli de. Crime, polícia e justiça no Brasil. São Paulo: Editora Contexto, 2014.

KANT DE LIMA, Roberto. Antropologia, direito e segurança pública: uma combinação heterodoxa. Cuadernos de Antropología Social, n. 37, p 43-57, 2013.

MACHADO, Martha de Toledo. A proteção constitucional de crianças e adolescentes e os direitos humanos. Barueri: Manole, 2003.

MISSE, Michel. Malandros, marginais, vagabundos e a acumulação social da violência no Rio de Janeiro. 1999. Tese (Doutorado em Sociologia) - Instituto Universitário de Pesquisas do Rio de Janeiro, Uerj, Rio de Janeiro, 1999.

MISSE, Michel. Crime e violência no Brasil contemporâneo: Estudos de sociologia do crime e da violência urbana. Rio de Janeiro: Lumen Juris, 2011.

MISSE, Michel. Sujeição Criminal. In: LIMA, Renato Sérgio de; RATTON, José Luiz; AZEVEDO, Rodrigo Ghiringhelli de. Crime, polícia e Justiça no Brasil. São Paulo: Editora Contexto, 2014.

MISSE, Michel. Sobre a construção social do crime no Brasil: esboços de uma interpretação. In: MISSE, Michel. Acusados e acusadores: estudos sobre ofensas, acusações e incriminações. Rio de Janeiro: Revan, 2008.

OLIVEIRA, Luciano. Relendo "Vigiar e punir". Dilemas: Revista de Estudos de Conflito e Controle Social, v. 4, n. 2, p. 309-338, abr./maio/jun. 2011.

OLIVEIRA, Luciano. Do nunca mais ao eterno retorno. Uma reflexão sobre a tortura. São Paulo: Brasiliense, 2009. OLIVEIRA, Luciano. Sua excelência o comissário e outros ensaios de sociologia jurídica. Rio de Janeiro: Letra Legal Editoria, 2004.

PAVARINI, Massimo. Control y dominacion: teorias criminológicas burguesas e proyecto hegemónico. México: Siglo Veintiuno Editores, 1983.

PEIRANO, Mariza. A favor da etnografia. Rio de Janeiro: Relume-Dumará, 1995.

PORTO, Maria Stella Grossi. Crenças, valores e representações sociais da violência, Sociologias, n. 16, p. 250-273, 2006.

PRANDO, Camila Cardoso de Mello. A contribuição do discurso criminológico latino americano para a compreensão do controle punitivo moderno, controle penal na América Latina. Veredas do Direito, Belo Horizonte v. 3, n. 6, p. 77-93, jul./dez. 2006.

ROSENN, Keith S. O jeito na cultura juridical brasliera. Rio de Janeiro: Renovar, 1998.

SCHUCH, Patrice. Práticas de justiça: uma etnografia do "campo de atuação ao adolescente infrator" no Rio Grande do Sul, depois do Estatuto da Criança e do Adolescente. 2005. Tese (Doutorado em Antropologia) UFRS, Porto Alegre, 2005.

SÊDA, Edson. Os eufemistas e as crianças no Brasil. Rio de Janeiro: Adês, 1999, p. 1-16.

SCHWARCZ, Lilian. O espetáculo das raças. Cientistas, instituições e questão racial no Brasil 1870-1930. Rio de Janeiro: Companhia das Letras, 1993.

SOARES, Luiz Eduardo; BILL, M. V.; ATHAYDE, Celso. Cabeça de porco. Rio de Janeiro: Objetiva, 2005. p. 205.

SOZZO, Maximo. Traduttore traditore. Traducción, importación cultural e história del presenta de la criminología en America Latina. Cuadernos de Doctrina y Jurisprudencial penal, Argentina, n. 13, p. 353-427, 2003.

TEIXEIRA, Cesar Pinheiro. A construção social do ex-bandido": um estudo sobre sujeição criminal e pentecostalismo. Rio de Janeiro: 7 Letras, 2011.

VARGAS, Joana Domingues. Adolescentes infratores no Rio de Janeiro: violência e violação de direitos fundamentais. Revista CFCH, ano 2, n. 4, dez. 2011. 
VIEIRA, Oscar Vilhena. Reciprocidade e o jovem infrator. Sócio-educação no Brasil: adolescente em conflito com a lei. Experiências de medidas sócio-educativa. São Paulo: Ilanud, 1997. p. 99-103.

ZAFFARONI, E. R Em busca das Penas Perdidas: a perda da legitimidade do sistema penal. Rio de Janeiro: Ed. Revan, 1991.

ZAFFARONI, E. R. Criminología: aproximación desde un margen. Bogotá: Editorial Temis, 2003.

ZALUAR, Alba. Nem líderes, nem heróis: a verdade da história oral. Presença. Revista de Cultura e Política, n. 14, p. 111-128, 1989. 